\title{
Improved DFIG Capability during Asymmetrical Grid Faults
}

\author{
Zhou, Dao; Blaabjerg, Frede
}

Published in:

Proceedings of the 41th Annual Conference of IEEE Industrial Electronics Society, IECON 2015

DOI (link to publication from Publisher):

10.1109/IECON.2015.7392255

Publication date:

2015

Document Version

Accepted author manuscript, peer reviewed version

Link to publication from Aalborg University

Citation for published version $(A P A)$ :

Zhou, D., \& Blaabjerg, F. (2015). Improved DFIG Capability during Asymmetrical Grid Faults. In Proceedings of the 41th Annual Conference of IEEE Industrial Electronics Society, IECON 2015 (pp. 001152 - 001157). IEEE Press. https://doi.org/10.1109/IECON.2015.7392255

\section{General rights}

Copyright and moral rights for the publications made accessible in the public portal are retained by the authors and/or other copyright owners and it is a condition of accessing publications that users recognise and abide by the legal requirements associated with these rights.

- Users may download and print one copy of any publication from the public portal for the purpose of private study or research.

- You may not further distribute the material or use it for any profit-making activity or commercial gain

- You may freely distribute the URL identifying the publication in the public portal -

\section{Take down policy}

If you believe that this document breaches copyright please contact us at vbn@aub.aau.dk providing details, and we will remove access to the work immediately and investigate your claim. 


\title{
Improved DFIG Capability during Asymmetrical Grid Faults
}

\author{
Dao Zhou, Frede Blaabjerg \\ Department of Energy Technology \\ Aalborg University \\ Pontoppidanstraede 101, Aalborg, DK-9220, Denmark \\ zda@et.aau.dk, fbl@et.aau.dk
}

\begin{abstract}
In the wind power application, different asymmetrical types of the grid fault can be categorized after the $Y / d$ transformer, and the positive and negative components of a single-phase fault, phase-to-phase fault, and two-phase fault can be summarized. Due to the newly introduced negative and even the natural component of the Doubly-Fed Induction Generator (DFIG) stator flux during the fault period, their effects on the rotor voltage can be investigated. It is concluded that the phase-to-phase fault has the worst scenario due to its highest introduction of the negative stator flux. Afterwards, the capability of a 2 MW DFIG to ride through asymmetrical grid faults can be estimated at the existing design of the power electronics converter. Finally, a control scheme aimed to improve the DFIG capability is proposed and the simulation results validate its feasibility.
\end{abstract}

\section{INTRODUCTION}

The wind power generation has gained increasing popularity and will reach around $400 \mathrm{GW}$ at the end of 2015 [1]. Meanwhile, a Doubly-Fed Induction Generator (DFIG) structure is still the most favorite concept preferred by the wind turbine manufacturers due to its economic power converter and independent control of the active power and reactive power [2]-[5]. However, the stricter grid codes on the Low Voltage Ride-Through (LVRT) prevent the overwhelming use of this concept because of the direct linking between the stator and power grid, which causes high rotor electromotive force (emf) that can result in the overvoltage and overcurrent of the Rotor-Side Converter (RSC) in the back-to-back power converters.

Recently, the Transmission System Operator (TSO) starts to follow with the interest of the asymmetrical grid fault [6]. Although some work has been focused on negative current control in the case of unbalanced network condition [7], the control objective may change from the constant power output or smooth current to the successful ride-through of the DFIG. As a consequence, this paper addresses the DFIG performance, investigates the DFIG capability, and tries to propose a control method to improve the DFIG capability at different asymmetrical faults.
The structure of the paper is organized as follows. It starts to classify asymmetrical grid faults, when the Y/d transformer in the wind turbine system is taken into account. Then, the component constitution of the stator flux is investigated, and their effects on the rotor voltage are analyzed as well as the DFIG capability in terms of the various asymmetrical faults. Afterwards, a control scheme is proposed to enhance the DFIG capability and it is verified with the simulation results. Finally, some concluding remarks are summarized in the last section.

\section{ClASSIFICATION OF ASYMMETRICAL FAUlt TyPES}

A lot of grid fault types can be classified in the power system, and they are mainly consisted of symmetrical fault (three-phase fault $3 \Phi-\mathrm{g}$ ) and asymmetrical faults (single-phase fault $\Phi$-g, phase-to-phase fault $2 \Phi$, and two-phase fault $2 \Phi$-g) [8], [9]. Compared to the symmetrical grid fault, an asymmetrical grid fault contains the negative component and the even zero component. Due to the existence of a $\mathrm{Y} / \mathrm{d}$ transformer in the power transmission system, the zero component of the voltage circulates within the delta transformer and cannot be propagated, so the type of the asymmetrical grid fault may be changed remarkably.

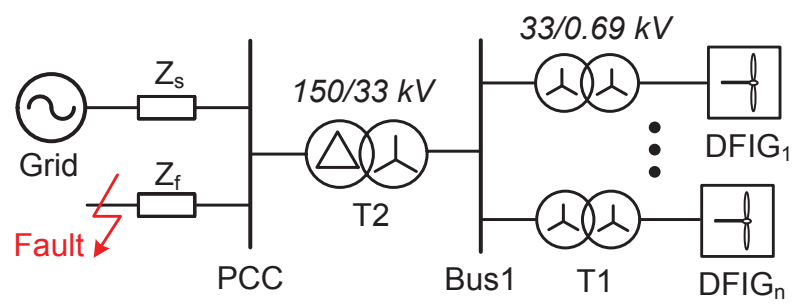

Fig. 1. Typical configuration for a wind farm linking to the power grid.

A typical configuration between the power grid and a wind farm is shown in Fig. 1 [8]. T1 represents the step-up transformer in order to increase the low voltage of wind turbine terminals to the medium voltage (Bus1) used in the collection grid of the wind farm, which is normally located in the nacelle of the wind turbine. Then, a large step-up 
transformer T2, sized at the nominal capacity of the wind farm, is used to increase collection-grid voltage to the transmissionlevel voltage (PCC).

The short-circuit fault normally happens at the terminal of the transmission line. Depending on the source impedance $Z_{s}$ and the impedance between the PCC and fault location $Z_{f}$, the dip level $p_{\text {dip }}$ can be defined as,

$$
p_{\text {dip }}=\frac{Z_{s}}{Z_{f}+Z_{s}}
$$

For simplicity, only the parasitic resistance is considered in the transmission line, which avoids the phase angle jump between the grid and PCC voltage. It can be seen that the dip level can be varied from 0 to 1 because of the fault distance to the PCC.

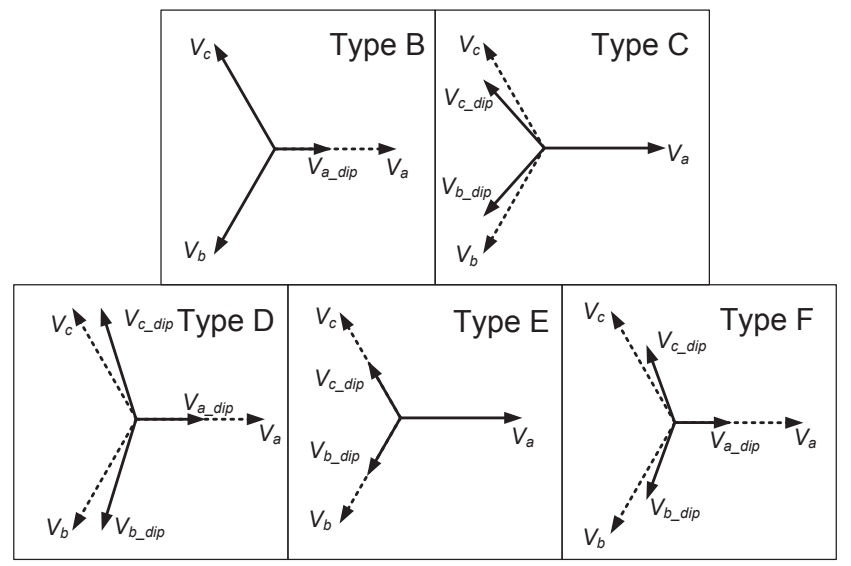

Fig. 2. Classification of various dip types: Phasors of threephase voltage before (dotted) and during fault (solid) are displayed.

Table I

Positive, NeGATIVE AND ZERO COMPONENTS OF ASYMMETRICAL FAULTS THROUGH Y/D TRANSFORMER.

\begin{tabular}{|c|c|c|c|c|}
\hline \multicolumn{2}{|r|}{ Fault types } & $\Phi-g$ & $2 \Phi$ & $2 \Phi-g$ \\
\hline \multirow{3}{*}{ PCC } & Dip level & $\mathrm{p}_{\mathrm{dip}}$ & $\mathrm{p}_{\mathrm{dip}}$ & $\mathrm{p}_{\mathrm{dip}}$ \\
\hline & Classification & B & $\mathrm{C}$ & $\mathrm{E}$ \\
\hline & $\begin{array}{l}\text { Pos., neg. and } \\
\text { zero components }\end{array}$ & $\begin{array}{c}1-\mathrm{p}_{\mathrm{dip}} / 3 \\
-\mathrm{p}_{\mathrm{dip}} / 3 \\
-\mathrm{p}_{\mathrm{dip}} / 3\end{array}$ & $\begin{array}{c}1-\mathrm{p}_{\mathrm{dip}} / 2 \\
\mathrm{p}_{\mathrm{dip}} / 2 \\
0\end{array}$ & $\begin{array}{c}1-2 \mathrm{p}_{\mathrm{dip}} / 3 \\
\mathrm{p}_{\mathrm{dip}} / 3 ; \\
\mathrm{p}_{\mathrm{dip}} / 3\end{array}$ \\
\hline \multirow[b]{2}{*}{ Bus1 } & Classification & $\mathrm{C}$ & $\mathrm{D}$ & $\mathrm{F}$ \\
\hline & $\begin{array}{l}\text { Pos., neg. and } \\
\text { zero components }\end{array}$ & $\begin{array}{c}1-\mathrm{p}_{\mathrm{dip}} / 3 \\
\mathrm{p}_{\mathrm{dip}} / 3 \\
0\end{array}$ & $\begin{array}{c}1-\mathrm{p}_{\mathrm{dip}} / 2 \\
-\mathrm{p}_{\mathrm{dip}} / 2 \\
0\end{array}$ & $\begin{array}{c}1-2 \mathrm{p}_{\mathrm{dip}} / 3 \\
-\mathrm{p}_{\mathrm{dip}} / 3 \\
0\end{array}$ \\
\hline
\end{tabular}

Assuming that various asymmetrical grid faults occur at the same location, the calculation of the voltage at the turbine terminal will be different [10]. In the case of the dip level, the positive, negative and zero components of the voltages at PCC and Bus 1 are listed and summarized in Table I. As shown in Fig. 2, it can be seen that fault type can be changed through the $\mathrm{Y} / \mathrm{d}$ transformer. Moreover, it is noted that the positive component remains the same, while the negative component becomes inverse. It is evident that the $2 \Phi$ fault introduces the highest negative component.

\section{StATOR FLUX EFFECTS ON ROTOR VOLTAGE}

Because of the existence of the $\mathrm{Y} / \mathrm{d}$ transformer, there is rare zero sequence voltage in the wind turbine system. However, due to the direct linking from the DFIG stator to the power grid, the negative sequence and even the natural stator flux may be introduced in the case of asymmetrical faults, and it challenges the DFIG to successfully ride through the fault period.

\section{A. Components of stator flux}

A popular DFIG model at the frame of an arbitrary speed $\omega$ is shown in Fig. 3 [7], [11], where the variables of the rotor side are transferred to the stator side. Correspondingly, the relationship between the stator voltage $u_{s}$ and the stator flux $\varphi_{s}$ can be found,

$$
\overline{u_{s}^{s}}=R_{s} \overline{i_{s}^{s}}+p \overline{\varphi_{s}^{s}}
$$

where $R_{s}$ and $i_{s}$ denote the stator resistance and stator current, $p$ denotes the differential operator, and subscript $s$ denotes the stator reference frame.

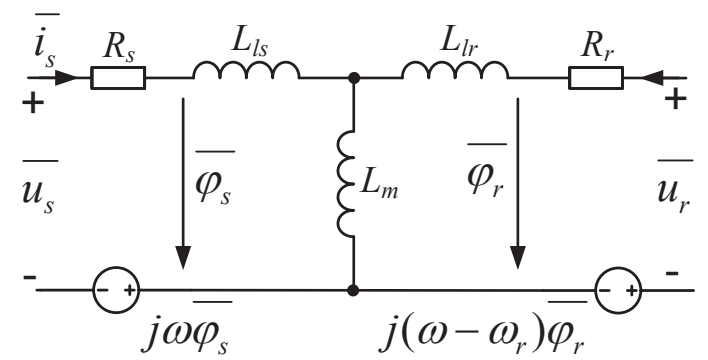

Fig. 3. Space vector representation of a DFIG model at an arbitrary speed.

For a MW-level DFIG used in wind turbines, the voltage drop across the stator resistance only contributes to $1 \%$ of the stator voltage [11], and this component can almost be neglected. Consequently, the stator flux becomes the integral of the stator voltage.

In the case of asymmetrical grid faults, in accordance with the positive and negative voltage components as listed in Table I, the positive and negative stator flux can be calculated based on (1). The negative stator flux rotates in the opposite direction of the positive stator flux, which leads to the steadystate elliptical trajectory from the original circular trajectory. However, as the stator flux cannot be changed abruptly, the natural flux $\varphi_{s n}$ may be introduced, whose value depends on the time instant of the fault occurrence [11], [12]. For different 
types of grid fault, the maximum and minimum natural stator flux component are summarized in Table II.

Table II

MAXIMUM AND MINIMUM NATURAL FLUX COMPONENTS AT VARIOUS TYPES OF ASYMMETRICAL FAULT.

\begin{tabular}{c|c|c|c}
\hline \hline Fault types & $\Phi-\mathrm{g}$ & $2 \Phi$ & $2 \Phi-\mathrm{g}$ \\
\hline Max. natural flux (pu) & $\mathrm{p}_{\text {dip }} / 3$ & $\mathrm{p}_{\text {dip }}$ & $\mathrm{p}_{\text {dip }}$ \\
\hline Min. natural flux (pu) & 0 & 0 & $\mathrm{p}_{\text {dip }} / 3$ \\
\hline \hline
\end{tabular}

\section{B. Effects of flux component}

Due to the DFIG model as shown in Fig. 3, since the stator flux and the rotor flux are coupled with the stator current and the rotor current, the rotor flux $\varphi_{r}$ can thereby be expressed by the stator flux $\varphi_{s}$ and rotor current $i_{r}$,

$$
\overline{\varphi_{r}}=\frac{L_{m}}{L_{s}} \overline{\varphi_{s}}+\sigma L_{r} \bar{i}_{r}
$$

where $L_{m}, L_{s}$ and $L_{r}$ denote the magnetizing inductance, the stator inductance and the rotor inductance, and $\sigma$ denotes the leakage coefficient.

Meanwhile, according to the voltage equation of the DFIG, the rotor voltage yields,

$$
\overline{u_{r}^{r}}=R_{r} \overline{i_{r}^{r}}+p \overline{\varphi_{r}^{r}}
$$

where $R_{r}$ denotes the rotor resistance, and subscript $r$ denotes the rotor reference frame.

Substituting (3) into (4), the rotor voltage can be related to the stator flux as well as the rotor current,

$$
\overline{u_{r}^{r}}=\frac{L_{m}}{L_{s}} p \overline{\varphi_{s}^{r}}+\left(R_{r}+\sigma L_{r} p\right) \overline{i_{r}^{r}}
$$

where the first term denotes the emf induced by the stator flux in the rotor $e_{r}$. The second term denotes the voltage drop across to the rotor resistance and transient inductor.

Accordingly, as the sequence of the stator voltage includes the positive and negative components during asymmetrical faults, the stator flux under rotor reference frame can be obtained based on (2) if the stator voltage rotating at an arbitrary speed $\omega$,

$$
\overline{\varphi_{s}^{r}}=\frac{U_{s}}{j \omega} e^{j\left(\omega-\omega_{r}\right) t}
$$

where $U_{s}$ denotes the phasor of the stator voltage, and $\omega_{r}$ denotes rotor speed.

Substituting (6) into (5), it can be inferred that in the case of the positive component $U_{s^{+}}$, the positive rotor emf $e_{r+}$ is almost the product of the slip $s$ and the positive stator voltage.

$$
\underline{e_{r+}}=\frac{L_{m}}{L_{s}} \mathbf{s} \cdot \underline{U_{s+}}
$$

However, if the negative component of the stator voltage $U_{s-}$ is taken into account, the negative rotor voltage $e_{r-}$ becomes,

$$
\underline{e_{r-}}=\frac{L_{m}}{L_{s}}(2-\mathrm{s}) \cdot \underline{U_{s-}}
$$

where the rotor emf is (2-s) times higher than the negative stator voltage. Normally, the slip value varies from -0.2 to 0.2 for the DFIG generation system, which results in much higher emf in case of the negative sequence stator voltage.

For the natural stator flux, since it stands still seen form the stator reference frame, it rotates at $\omega$ in respect to the rotor reference frame. The natural component of the stator voltage $e_{r 0}$ is deduced by,

$$
\underline{e_{r 0}}=\frac{L_{m}}{L_{s}}(1-\mathrm{s}) \cdot \underline{U_{s 0}}
$$

where $U_{s 0}$ denotes virtual equivalent natural stator voltage that leads to the existence of the natural stator flux.

\section{Capability of a $2 \mathrm{MW} D F I G$}

A case study of capability is analyzed at a 2 MW DFIG system, and the main parameters of the DFIG and its RSC are listed in Table III. During the normal operation, although the winding ratio between the stator and rotor behaves as step-up transformer, the yield rotor voltage inferred from (5) is much smaller than the stator voltage because the rated slip value is only -0.2 .

Table III

MAIN PARAMETERS OF 2 MW DFIG AND ITS RSC.

\begin{tabular}{c|c}
\hline \hline Power rating of DFIG $P_{s}$ & $2 \mathrm{MW}$ \\
\hline Speed range & $1050-1800 \mathrm{rpm}$ \\
\hline Rated stator voltage $U_{s}$ & $564 \mathrm{~V}$ \\
\hline Winding ratio between stator and rotor $k_{s r}$ & 0.369 \\
\hline Stator inductance $L_{s}$ & $2.95 \mathrm{mH}$ \\
\hline Rotor inductance $L_{r}$ & $2.97 \mathrm{mH}$ \\
\hline Magnetizing inductance $L_{m}$ & $2.91 \mathrm{mH}$ \\
\hline Leakage factor $\sigma$ & 0.033 \\
\hline Stator resistance $R_{s}$ & $1.688 \mathrm{~m} \Omega$ \\
\hline Rotor resistance $R_{r}$ & $1.524 \mathrm{~m} \Omega$ \\
\hline Power module in each arm of RSC & $1 \mathrm{kA} / 1.7 \mathrm{kV} ;$ \\
\hline DC-link voltage $U_{d c}$ & $1050 \mathrm{~V}$ \\
\hline Rated rotor voltage $U_{r}$ & $305 \mathrm{~V}$ \\
\hline Rated rotor current $I_{r}$ & $915 \mathrm{~A}$ \\
\hline \hline
\end{tabular}


As previously mentioned, various components of the stator flux may have different impacts on the emf. In the case of a single-phase fault, the introduced emf can also be categorized as the positive, negative and natural components. If the minimum natural stator flux is taken into account, the capability of the DFIG in the case of the $\Phi$-g fault can be estimated in Fig. 4(a) by summing up all emf components. It is noted that the negative component of the stator flux causes much higher rotor voltage than usual, which may even exceed the output voltage that dc-link can maximum provide $(2.5 \mathrm{pu}$ rotor current). Similarly, the capability in the cases of $2 \Phi$ fault and $2 \Phi$-g fault of the DFIG can be seen in Fig. 4(b) and Fig. 4(c), respectively. Due to the smallest positive rotor voltage at synchronous operation, the DFIG can endure the highest dip level among various rotor speeds. Besides, as the $2 \Phi$ fault has the highest negative component of the stator flux, the ridethrough capability of the DFIG becomes worst under this situation $(0.29 \mathrm{pu}$ at rotor speed of $1050 \mathrm{rpm})$.

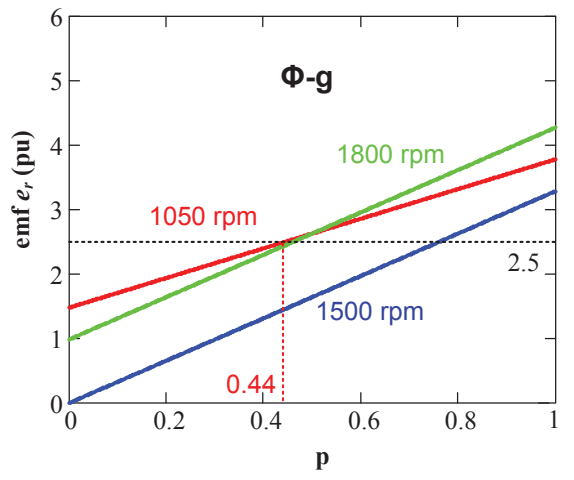

(a)

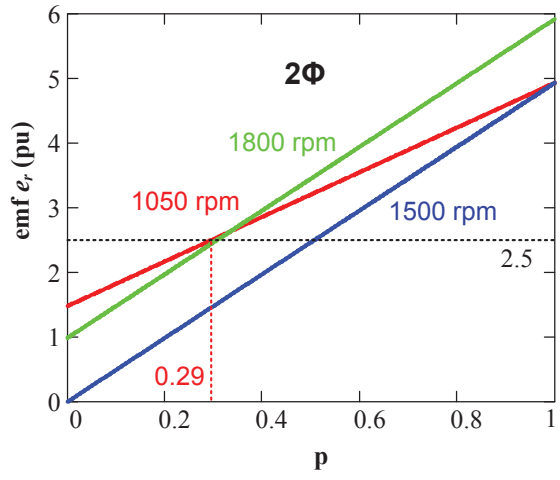

(b)

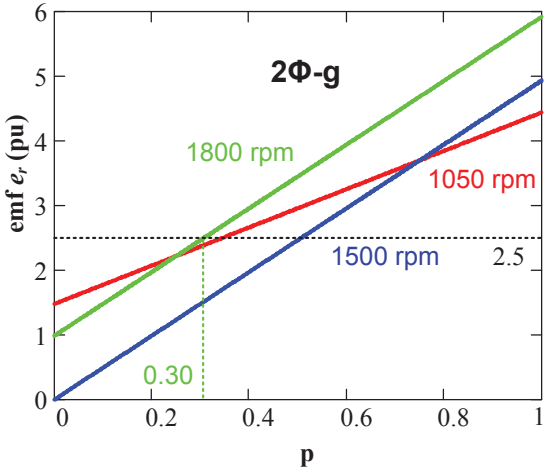

(c)

Fig. 4. Capability of the DFIG for various asymmetrical grid faults. (a) $\Phi$-g fault; (b) $2 \Phi$ fault; (c) $2 \Phi$-g fault.

\section{CONTROL OF ROTOR CURRENT}

Due to the existence of the negative stator flux, the control objective of the DFIG may be shift from the maximum power generation in order to realize the Low Voltage Ride-Though (LVRT) requirement. This section starts with the DFIG model seen from the rotor side. Then, the DFIG capability during asymmetrical grid faults will be improved by using the proper rotor current control.

\section{A. Control target of rotor current}

According to voltage equation of the DFIG rotor-side as expressed in (5), the DFIG model viewed from the rotor-side can be established in Fig. 5. It is noted that regardless of the positive or negative sequence the model remains the same.

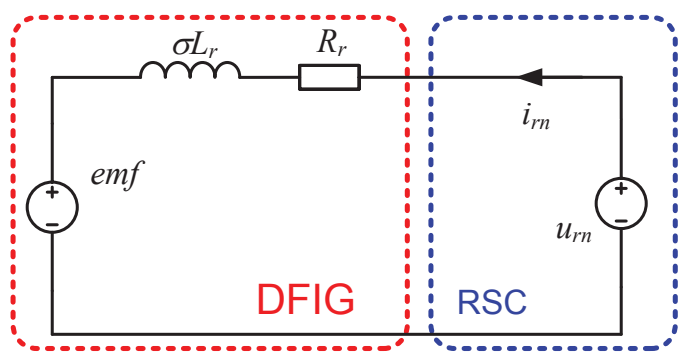

Fig. 5. Positive and negative DFIG model viewed from rotorside.

During the normal grid condition, if the super-synchronous operation is used as a case study, the phasor diagram of the DFIG stator and rotor variables are shown in Fig. 6(a). In order that the stator current is controlled in the opposite direction of the stator voltage, the rotor current is almost in reverse with the stator current. As the rotor transient reactance value is dominant compared to the rotor resistance, the voltage across the rotor resistor and transient inductor ${\underline{U_{R L+}}}_{\text {is lagging }}$ 90 degree in respect to the rotor current. As a result, the caused rotor voltage is almost the same as the emf, and the control objectives focus on the maximum power generation as well as the excitation supply in order to realize unity power factor in the DFIG stator-side.

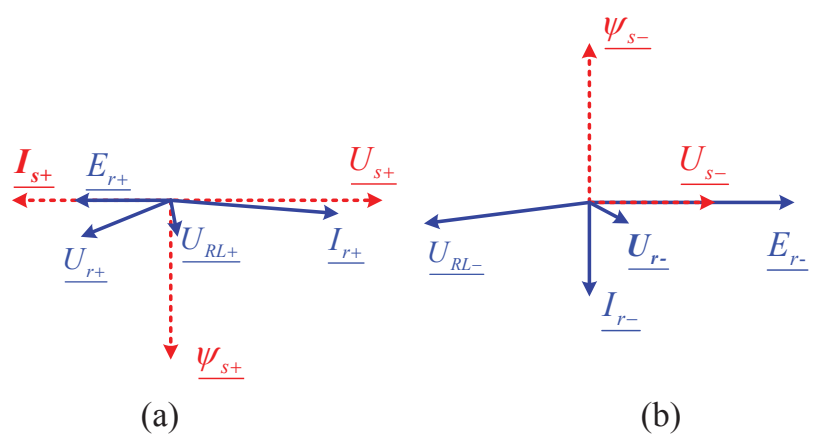

Fig. 6. Phasor diagram of DFIG stator and rotor variables. (a) Positive component; (b) Negative component. (Note: supersynchronous operation is used as a case study.)

In the case of asymmetrical faults, as mentioned before, the negative sequence of the stator flux introduces significant increase of the emf, which easily saturates the RSC. In order to enhance the capability of the DFIG, the control target is expected to switch from the active and reactive power control to the minimum rotor voltage, and this can be achieved by controlling the rotor current in the opposite direction of the negative stator flux. As shown in Fig. 6(b), since the negative 
stator flux is leading 90 degree with respect to negative stator voltage, the voltage across the rotor resistor and transient inductor $U_{R L-}$ is almost in the opposite direction in respect to negative stator voltage. As the negative emf is in the same direction with the negative stator voltage, this control can cancel out the effect of the negative emf, and causes lower rotor voltage.

\section{B. Improved DFIG capability}

According to voltage equation of the DFIG rotor-side as expressed in (5), the relationship between the rotor voltage and rotor current can be found. Due to the power rating of the IGBT module as listed in Table III, up to 2.0 pu rotor current can be applied. In order to have the similar loading stress of power semiconductor in the normal operation, $1.0 \mathrm{pu}$ rotor current is selected. The DFIG capability under $\Phi$-g fault can be summarized and found in Fig. 7(a), where the DFIG LVRT capability is restricted by the rotor speed of $1050 \mathrm{rpm}$. Under this circumstance, the RSC can withstand up to 0.80 dip level, which is remarkably improved than 0.44 dip level of the traditional control. Similarly, the DFIG capability in the cases of $2 \Phi$ and $2 \Phi-g$ faults can be summarized in Fig. 7(b) and Fig. 7(c), respectively. It can be seen that the rotor speed at 1050 rpm will limit the DFIG fault ride-through capability. However, the capability ranges become 0.54 and 0.61 dip level, which are much more enhanced compared to the traditional control as shown in Fig. 4(b) and Fig. 4(c).

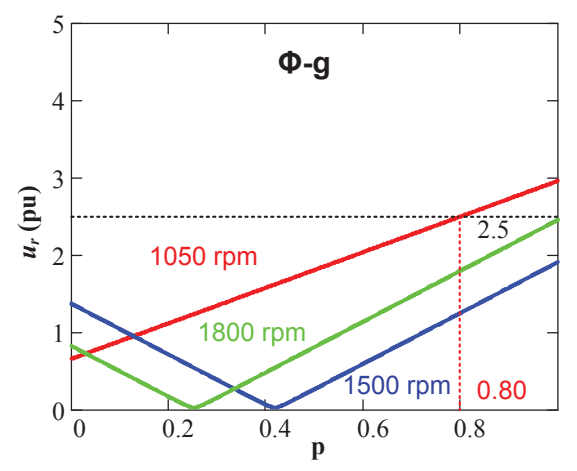

(a)

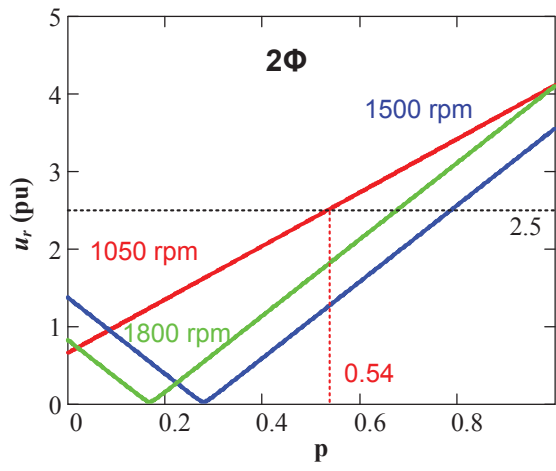

(b)

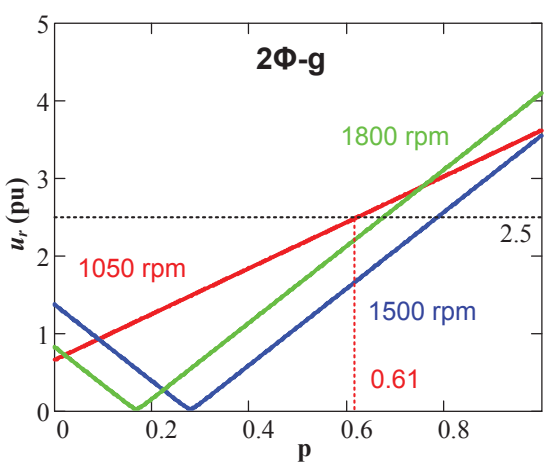

(c)

Fig. 7. Improved DFIG capability using 1.0 pu negative rotor current. (a) $\Phi$-g fault; (b) $2 \Phi$ fault; (c) $2 \Phi$-g fault.

\section{SimUlation VALIDATION}

In order to reduce the rotor voltage in asymmetrical faults, the control scheme of the RSC is comprehensively addressed. Moreover, the improved DFIG capability is validated by simulation in the case of the $\Phi$-g fault.

\section{A. Control scheme}

In the condition of the positive $\mathrm{dq}^{+}$frame, the negative component during the asymmetrical grid fault will no longer become a dc component, but an ac component with the frequency of $100 \mathrm{~Hz}$. It prevents the application of traditional PI controller, which can only track the dc component without any error. Correspondingly, a negative $\mathrm{dq}^{-}$frame is introduced, and a notch filter is also applied to extract the positive or negative component after the positive $\mathrm{dq}^{+}$or negative $\mathrm{dq}^{-}$ frame.

As mentioned in [7], the negative component of the rotor current reference can be set in order to achieve balanced stator current, balanced rotor current, constant output active power, and constant electromagnetic torque under unbalanced network conditions. However, this is the long-term steadystate condition because of the weak power grid, and the focus will be changed if a sudden asymmetrical fault happens, which highlights the successful ride through of the DFIG RSC. Since the negative component of the stator voltage causes very high

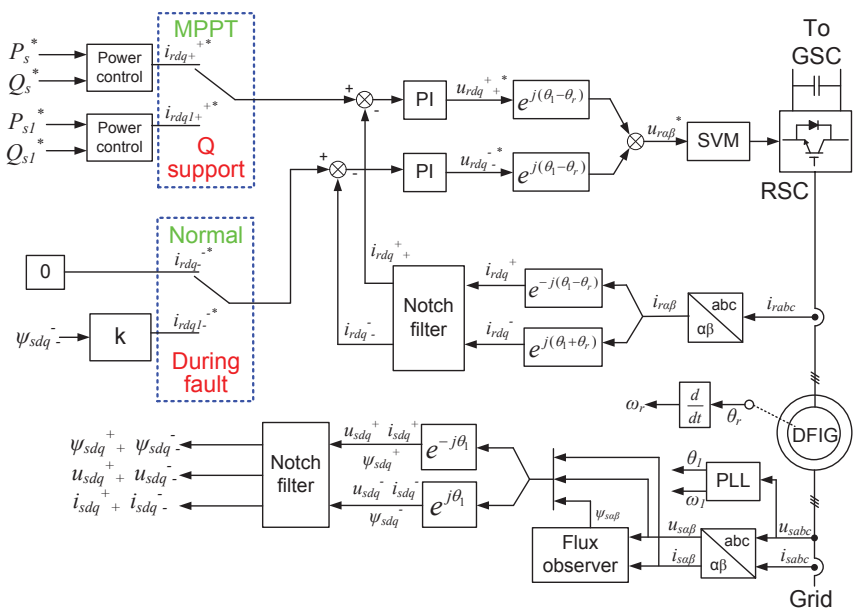

Fig. 8. Control scheme of the DFIG to reduce the required rotor voltage during asymmetrical faults.

emf in the DFIG rotor-side, the rotor current is controlled in the opposite direction with the negative stator flux, which makes the voltage across the rotor resistance and transient inductor counteract the emf. The amplitude of the rotor current reference is decided by the gain coefficient $\mathrm{k}$. The complete control scheme of the RSC is then shown in Fig. 8. It is noted that in normal situation, the Maximum Power Point Traction (MPPT) is implemented through the positive component of the rotor current, while there is no negative component of the 
rotor current due to no negative component exists in the DFIG system. During the fault period, the reference of the positive component of the rotor current is set to supply the reactive power according to the grid codes, while the reference of the negative component of the rotor current becomes to follow the negative stator flux.

\section{B. Simulation result}

The 2 MW DFIG is simulated in order to verify the improved capability under the asymmetrical fault, in which the $\Phi$-g fault is used as a case study. Assuming the dc capacitor is large enough to maintain a constant dc voltage, and the DFIG operates at $1800 \mathrm{rpm}$, in case of the dip level of 0.5 , the traditional vector control cannot ride through as shown in Fig. 4(a), while the proposed control can withstand this fault successfully as shown in Fig. 7(a).

As shown in Fig. 9(a), the reference of the rotor current remains the same in the traditional vector control, where no negative component of the rotor current is injected. It is noted that during the fault period the current reference cannot be well tracked, which indicates the saturation of the RSC. Meanwhile, the maximum rotor current almost reaches $4.0 \mathrm{pu}$, which can easily breakdown the power modules used in the RSC. The proposed control scheme is shown in Fig. 9(b). The positive rotor current reference reduce to zero, while the negative current is $1.0 \mathrm{pu}$ to track the opposite direction of the negative stator flux. It can be seen that the rotor current can be followed after dozens of milliseconds, and the maximum rotor current is almost $1.0 \mathrm{pu}$, which implies the successful fault ride-through.

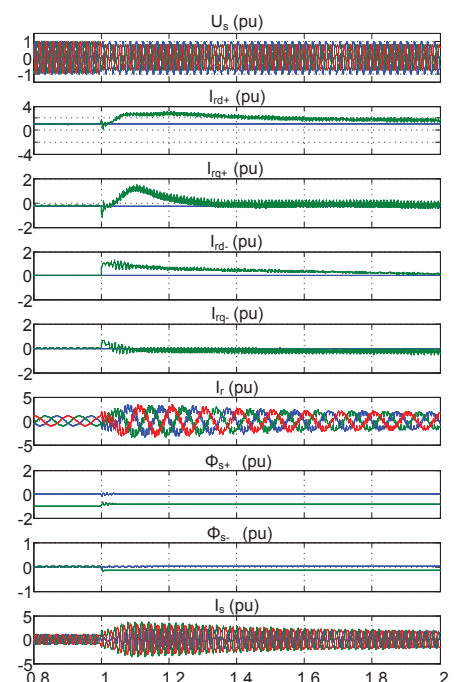

(a)

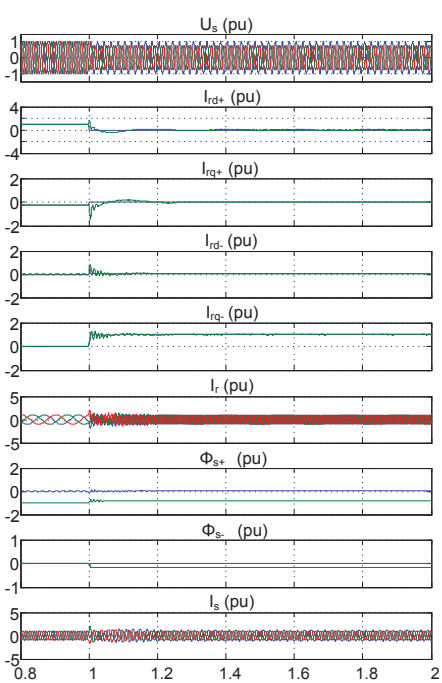

(b)
Fig. 9. Simulated results of the DFIG in the case of the $\Phi-g$ fault at the dip level of 0.5. (a) Traditional vector control; (b) Proposed control.

\section{CONCLUSION}

This paper starts with the classification of the various types of asymmetrical grid fault after the $\mathrm{Y} / \mathrm{d}$ transformer existing in the wind turbine system, which can be summarized by the certain amounts of the positive and the negative voltage component. Then, the constitution of stator flux is investigated in the case of asymmetrical grid fault, and the negative component of the stator flux is inevitably introduced, which significantly reduces the DFIG capability due to the fact that it causes the higher rotor emf. It is concluded that the compared with various asymmetrical grid faults, the phase-to-phase grid fault has the most severe impacts on the low voltage ridethrough capability. As a consequence, the control scheme aiming at rotor voltage reduction is proposed by injecting the rotor current in the opposite direction of the negative stator flux, and thus improves the DFIG capability. Finally, the simulation results validate its effectiveness in the case of the single-phase grid fault.

\section{References}

[1] Global wind report 2014. (http://www.gwec.net)

[2] H. Polinder, J. A. Ferreira, B. B. Jensen, A. B. Abrahamsen, K. Atallah, R. A. McMahon, "Trends in wind turbine generator systems," IEEE Journal of Emerging and Selected Topics in Power Electronics, vol. 1, no. 3, pp.174-185, Sep. 2013.

[3] North American wind power. Top 15 Wind turbine suppliers of 2013 revealed. (http://www.nawindpower.com)

[4] D. Zhou, F. Blaabjerg, T. Franke, M. Tonnes, M. Lau, "Reduced cost of reactive power in doubly fed induction generator wind turbine system with optimized grid filter," IEEE Trans. on Power Electronics, vol. 30, no. 10, pp. 5581-5590, Oct. 2015.

[5] D. Zhou; F. Blaabjerg, M. Lau, M. Tonnes, "Thermal behavior of doubly-fed induction generator wind turbine system during balanced grid fault," in Proc. of APEC 2014, pp. 3076-3083, 2014.

[6] SDL WindV, "Ordinance on system services by wind energy plants".

[7] L. Xu, Y. Wang, "Dynamic modeling and control of DFIGbased wind turbines under unbalanced network conditions," IEEE Trans. on Power Systems, vol. 22, no. 1, pp. 314-323, Feb. 2007.

[8] M. Mohseni, S. Islam, M. A. S. Masoum, "Impacts of symmetrical and asymmetrical voltage sags on DFIG-based wind turbines considering phase-angle jump, voltage recovery, and sag parameters," IEEE Trans. on Power Electronics, vol. 26, no. 5, pp. 1587-1598, May 2011.

[9] G. Saccomando, J. Svensson, A. Sannino, "Improving voltage disturbance rejection for variable-speed wind turbines," IEEE Trans. on Energy Conversion, vol. 17, no. 3, pp. 422-428, Sep. 2002.

[10] M. H. J. Bollen, Understanding Power Quality Problems: Voltage Sags and Interruptions. New York: IEEE Press, 1999

[11] G. Abad, J. Lopez, M. Rodriguez, L. Marroyo, G. Iwanski, Doubly fed induction machine-modeling and control for wind energy generation. Piscataway, NJ: IEEE Press, 2011.

[12] H. Geng, C. Liu, G. Yang, "LVRT capability of DFIG-based WECS under asymmetrical grid fault condition," IEEE Trans. on Industrial Electronics, vol. 60, no. 6, pp. 2495-2509, Jun. 2013. 